\title{
Clinical course of hurricane keratopathy
}

\author{
Harminder S Dua, Jose A P Gomes
}

\begin{abstract}
Backgroundlaims-"Hurricane keratopathy" is the name given to the whorl pattern, highlighted with fluorescein, seen in situations where corneal epithelial cell turnover is exaggerated. Although the condition is well described, follow up data on patients with this condition and its sequelae have only been reported in corneal graft patients. The aim was to study the clinical course of hurricane keratopathy in corneal graft patients and contact lens wearers, and to document any sequelae of this condition.

Methods-Hurricane keratopathy, occurring in 20 eyes with corneal grafts and $\mathbf{1 6}$ eyes (six bilateral) wearing rigid gas permeable contact lenses, was studied and followed. The occurrence, pattern, progress, resolution, and residual effects of the whorls were noted.
\end{abstract}

Results-Hurricane keratopathy was noted to occur in grafts as previously reported and also in contact lens wearers, which has hitherto not been reported. The whorls usually appeared within the first 3 weeks postoperatively and persisted up to 4 months. A small epithelial defect (11.1\%), heaped epithelial cells (5.6\%), and a nebular grade opacity $(2.8 \%)$, were the only significant sequelae noted at the epicentre of the whorls. Resolution occurred from the periphery towards the centre of the cornea.

Conclusions-The whorl pattern is sustained as long as the stimulus for increased cell turnover is maintained. Once this stimulus is eliminated, the pattern tends to resolve spontaneously.

(Br f Ophthalmol 2000;84:285-288)

Department of Ophthalmology, University of Nottingham

H S Dua

Cornea and External Eye Disease Service, Federal University of Sao Paulo (UNIFESP), Brazil

J A P Gomes

Correspondence to: H S Dua, Department of Ophthalmology, B floor,

South Block, University

Hospital, Queen's Medical

Centre, Nottingham

NG7 2UH

Accepted for publication 19 November 1999
During normal epithelial turnover, the path taken by epithelial cells, as they migrate from the periphery to the centre of the cornea, is not visible. However, in several diverse clinical conditions, the cells are rendered visible by the intracellular deposition of substances like pigment, iron, drug metabolites, glycogen, and sphingolipid..$^{1-3}$ In such conditions, a vortex or whorl pattern is apparent on the corneal surface and is called vortex keratopathy or cornea verticillata. ${ }^{13}$

The term "hurricane keratopathy" is used to describe the whorled or vortex distribution of cells that often occurs in the corneal epithelium during states of increased replicative turnover. ${ }^{4}{ }^{5}$ It differs from cornea verticillata in that the pattern is highlighted by fluorescein staining and does not represent the deposition of any substance. ${ }^{5}$ It was initially considered to be restricted to grafted corneas and thought to be the toxic effect of topical steroids, or caused by the preferential migration of cells between graft sutures. ${ }^{24}$

Hurricane keratopathy was later reported to occur in eyes that had not undergone a corneal graft procedure but showed evidence of chronic epithelial breakdown and healing. ${ }^{5-7}$ Dua et $a l^{56}$ noted that the whorled configuration of cells was "clockwise" in the majority of cases and hypothesised that this represented a response of corneal epithelial cells to ocular electromagnetic fields.

The aim of this study was to follow the clinical course of hurricane keratopathy occurring in corneal grafts and in non-grafted corneas.

\section{Patients and methods}

Thirty seven "hurricanes" in 36 eyes of 30 patients were studied. Only patients with hurricane keratopathy were recruited into the study. Six patients had bilateral hurricane keratopathy and in one patient the condition recurred in the same eye. There were 10 males and 20 females with a mean age of 61 (SD 13.3) years. The patients were examined by fluorescein staining and slit lamp biomicroscopy, and the location, direction (clockwise or anti-clockwise, Fig 1), relation to sutures, progression and resolution, and any residual effect on the cornea, were noted. The symptoms of the patients were also recorded. The duration of the keratopathy was measured from the time of inclusion in the study till the end of the follow up period. This underestimates the actual duration of the hurricane pattern as it may have been present for varying periods of time before the day of diagnosis and inclusion in the study. Mean follow up was for 1 year (9 months to 16 months). Patients were examined for a minimum of six and a maximum of eight times during the follow up period. Corneal graft patients had all received prednisolone acetate $1 \%$, drops four times a day for 2 months after the graft, thrice a day for 2 months, and twice a day for the next 2 months. The steroid was reduced to once a day or once every other day in patients who had had the graft over 6 months. At the time of inclusion in the study, patients who had had the graft for 6 months or more were advised to stop topical steroid medication and were treated with preservativefree artificial tears (hypromellose $0.3 \%$ ) four to six times a day. Contact lens patients were instructed to reduce the wear time to a maximum of 8 hours a day and to use artificial tear drops (hypromellose).

\section{Results}

Of the 36 eyes, $20(55.6 \%)$ had penetrating keratoplasty and $16(44.4 \%)$ (six bilateral) wore rigid gas permeable (RGP) contact 
A

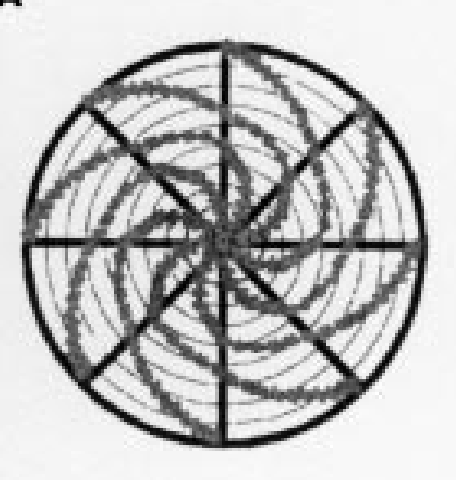

B

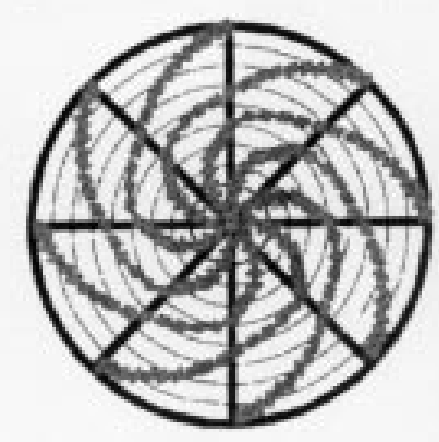

Figure 1 (A) Diagram representing a clockwise whorl. When a whorl on either eye conformed to the appearance in $(A)$, it was deemed to be a clockwise whorl. (B) Diagram representing an anti-clockwise whorl. When a whorl on either eye conformed to the appearance in (B), it was deemed to be an anti-clockwise whorl.

lenses. Keratoplasty was performed for aphakic or pseudophakic bullous keratopathy in nine patients, for keratoconus in seven patients, and for other conditions such as Fuchs' endothelial dystrophy, herpes simplex keratitis related scarring, and graft failure in four patients. All eyes with corneal transplants were being treated with topical steroids (prednisolone acetate $1 \%$ ). Seventeen of the graft patients had 16 interrupted sutures and three had combined 12 interrupted and a 12 bite running suture. The suture material was $10-0$ nylon in all cases. Four patients had all sutures out and the remaining patients had between four and seven of the interrupted sutures out at the time of inclusion in the study. The running sutures in the three patients were still in place. Contact lenses were prescribed for keratoconus (12 eyes), high myopic astigmatism (one eye), and post-graft astigmatism (three eyes). All patients wore rigid gas permeable contact lenses. Five lenses were aspheric and the remaining 11 were standard lenses with a single curvature for the base curve. All lenses had varying degrees of corneal touch but the patients were tolerating the lenses well. The patients with keratoconus had worn their current contact lenses for an average of 13 months (10-15 months) and the graft patients had worn theirs for an average of 10 months (8-12 months). The patient with myopic astigmatism had worn her present lens for 6 months at the time of inclusion in the study. The average daily wear time

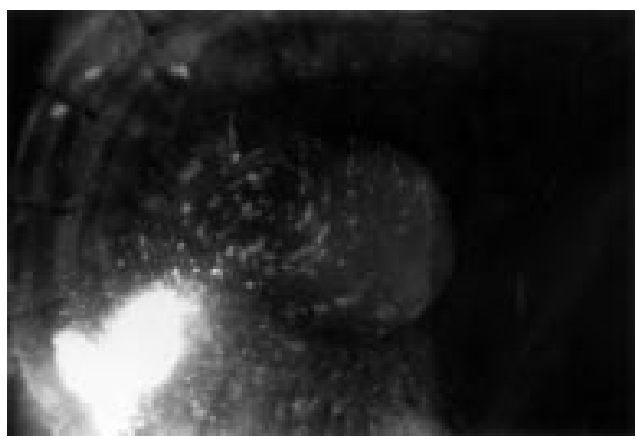

Figure 2 A temporally located clockwise whorl in the right eye of a patient with a corneal graft. There is no epithelial defect in the centre of the whorl.
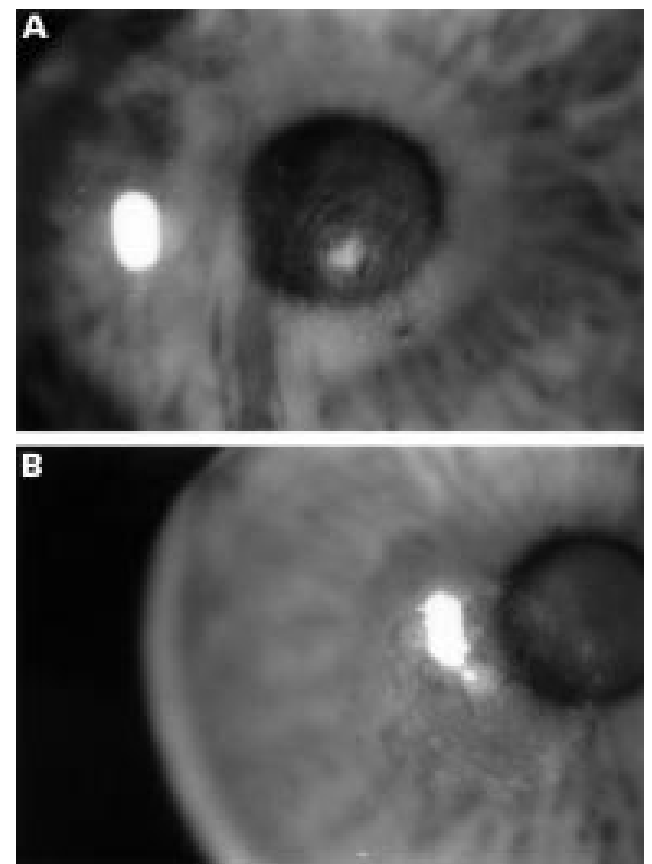

Figure 3 (A) A centrally located anti-clockwise whorl in the right eye of a patient with bilateral keratoconus wearing rigid gas permeable contact lenses. There is an epithelial defect at the epicentre of the whorl. (B) A centrally located clockwise whorl in the left eye of the same patient. There is a tiny epithelial defect at the epicentre of the whorl.

was 11 hours (10-14 hours). The three patients with corneal graft had all sutures out.

MEAN DURATION OF PERSISTENCE OF HURRICANES

In the post-keratoplasty group of patients the mean duration of the whorls was 29.9 (SD 22.5) weeks (median 23.5 weeks). In the contact lens wearing patients the mean duration was 42.8 (31.5) weeks (median 37.2 weeks). In three eyes in this group the hurricane pattern persisted for more than a year.

LOCATION OF THE HURRICANE (FIGS 2 AND 3)

The hurricane pattern was located centrally (apex of the whorl within the central $3 \mathrm{~mm}$ optical zone) in the cornea in 32 instances (31 eyes, twice in one eye) $(86.5 \%)$, inferiorly in one eye $(2.7 \%)$, medially in one eye $(2.7 \%)$, and temporally in three eyes $(8.1 \%)$. Most hurricanes in relation to contact lens wear were central in location. A medially displaced whorl was found in one patient with keratoconus and corresponded to the apex of the cone.

DIRECTION OF HURRICANE (FIGS 2, 3, 4)

The hurricane was clockwise in disposition in $33(89.2 \%)$ eyes and anti-clockwise in four eyes $(10.8 \%)$. Only one patient had recurrence of the whorl, which was clockwise on both occasions. One patient with bilateral hurricane keratopathy had a clockwise whorl in one eye and an anti-clockwise whorl in the other (Fig $3 \mathrm{~A}$ and $\mathrm{B})$.

RESIDUAL EFFECTS OF HURRICANES (FIG 3A, 4) Four eyes $(11.1 \%)$ had persistent corneal epithelial defects, two eyes (5.6\%) showed heaped aggregation of epithelial cells at the 


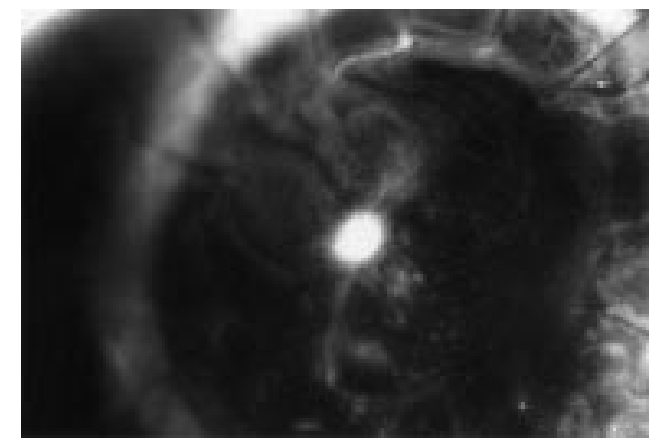

Figure 4 A centrally located clockwise whorl in the left eye of a patient with a corneal graft. There is an area of heaped epithelium at the centre, which is not staining with fluorescein.

centre of the whorl, and one eye (2.8\%) developed a subepithelial nebular grade opacity at the centre of the whorl. Three cases of central epithelial defects occurred in eyes with keratoconus. The single case of subepithelial scar occurred in a grafted cornea fitted with a contact lens.

The cells that formed the pattern were arranged radially for $2-3 \mathrm{~mm}$ at the limbus and then curved to the left in clockwise whorls, and right in anti-clockwise whorls. The curve became gradually more pronounced as the cells spiralled towards the apex of vortex. The fine lines of the vortex pattern were visible by slit lamp examination as white epithelial lines. These lines were, however, best visualised after staining with $2 \%$ sodium fluorescein, with intervening areas remaining unstained. It was not possible to determine whether the staining was intercellular or whether it was the cells themselves that stained. The staining intensity was maximal at the apex of the vortex. In nine cases there was an epithelial defect at the apex of the whorl. In five of these the defect healed with resolution of the whorl but in the other four the defect persisted.

The symptoms associated with hurricane keratopathy included mild ocular irritation, a foreign body sensation, lacrimation, photophobia, and slight blurring of vision. Instillation of artificial tears (preservative free) resulted in relief of symptoms and aided in resolution of the keratopathy. In most cases, the hurricane keratopathy resolved within a few weeks of cessation of steroid therapy. Resolution of hurricane keratopathy commenced with healing of the central epithelial defect in five of the nine cases where a defect was present. Resolution of the keratopathy itself commenced at the limbus and progressed centripetally. The process was not uniform, one area of the cornea cleared considerably while other area(s) still showed remnants of the original whorled pattern. Although the whorl pattern cleared from the periphery to the centre, occasionally a small component of the original whorl pattern, staining with fluorescein, persisted at the periphery. Hurricanes associated with rigid contact lens wear did not resolve until contact lens wear was discontinued. However, use of artificial tears did provide comfort to these patients.

\section{Discussion}

The whorled appearance seen in hurricane keratopathy probably reflects the path taken by corneal epithelial cells, during normal replicative turnover, as they migrate from the limbus to the centre of the cornea. This is not normally apparent owing to the slow rate of migration. ${ }^{56}$ When epithelial turnover is increased, as in the conditions studied, cell migration is rapid and tight intercellular adhesions may not form readily, allowing fluorescein to highlight individual cells or groups of cells. ${ }^{5}$ Use of topical steroid medication may contribute in this regard. ${ }^{24}$ Topical steroid therapy is known to cause superficial punctate keratitis and to delay epithelial wound healing. ${ }^{89}$ Although topical steroid usage has been a common underlying factor in many of the graft patients and others as well, the hurricane pattern developed just as distinctly in contact lens wearers who were not on any topical steroid medication. It is well recognised that ideal contact lens fitting is difficult to achieve in keratoconus patients and often in patients with post-graft astigmatism as well. ${ }^{10-12}$ Buxton ${ }^{10}$ reported that the contact lens in keratoconus is often "ill fitting" (by ametropic standards) and will frequently show apical touch. Unavoidable apical touch and/or rocking of the lens on the cornea leads to chronic punctate staining of the apex. With progression of the cone, the punctate staining can progress to become frank erosions or abrasions. ${ }^{10}{ }^{11} \mathrm{In}$ such cases, it is likely that there is an increased shedding (and replacement) of surface epithelial cells, increasing the cell turnover.

Hurricane keratopathy usually resolves spontaneously. Rarely, a persistent epithelial defect remains at the epicentre of the whorl. A subepithelial scar was noted in one case. Hurricane keratopathy associated with corneal grafts tends to resolve earlier than that due to rigid contact lens wear, where it may persist indefinitely. This once again illustrates that continual exaggerated shedding of epithelial cells with delayed epithelial healing, either because of topical steroid usage or contact lens wear, is probably a strong stimulus for the clinical development of the hurricane pattern. Resolution of the whorl pattern occurs from the periphery to the centre of the cornea.

In this study $89.2 \%$ of the whorls were clockwise. All seven patients with hurricane keratopathy reported in a previous study ${ }^{5}$ were also clockwise. This probably represents the response of corneal epithelial cells to ocular electromagnetic fields generated by the dipole of the eye. ${ }^{56} \mathrm{~A}$ theoretical basis for this has been elaborated in a previous study. ${ }^{5}$ The hurricane or whorl pattern has also been reproduced in vitro, by maintaining human corneal epithelial cell cultures in static magnetic fields. ${ }^{7}$ The in vitro study demonstrated that corneal epithelial cells cultured over bar magnets often developed dramatic whorls. Of the 15 whorls observed, $73.3 \%$ were clockwise and $26.7 \%$ were anti-clockwise. ${ }^{7}$ In both studies, in vivo and in vitro, the majority of the whorls were clockwise in predisposition. An exact explanation for this phenomenon is not yet known but 
available evidence tends to support the hypothesis that ocular electromagnetic fields may play a role in its occurrence. Mathers and Lemp ${ }^{13}$ studied the vortex pattern of epithelial cells in corneal graft patients using colour specular microscopy. They followed patients with corneal grafts in a prospective manner and noted that the greatest incidence of the vortex pattern was between 6 and 12 months after surgery but lasted up to 18 months. They did not report any sequelae as noted in this study. Lemp and Mathers ${ }^{2}$ and Mathers and Lemp ${ }^{13}$ have postulated that the vortex pattern is related to the graft sutures. They have reported that " ...subsequent to suture removal, the vortex pattern disappeared in all subjects." " They developed the theory that the sutures create a series of "gates" for preferential epithelial movement. In this study we observed the pattern in four corneal graft patients who had no remaining sutures and also noted it in patients with keratoconus and post-graft astigmatism, wearing rigid contact lenses. In a previous study we reported six patients with hurricane keratopathy, none of which had a corneal graft and only one was a contact lens wearer. ${ }^{5}$ The evidence therefore clearly indicates that, although the sutures may influence the way in which corneal epithelial cell migrate they are not responsible for the hurricane pattern.

A migration of cells in columns, during normal replicative turnover or within the advancing sheets of epithelium during wound healing, would facilitate development of the whorled configuration. If all cells at the limbus were to divide uniformly, any torsional effect would not be readily apparent. In this context, it has been shown that not all basal cells at the limbus are stem cells. Tseng ${ }^{14}$ estimated that only $30 \%$ of mouse limbal basal cells might represent stem cells. Davanger and Evensen ${ }^{15}$ suggested and provided preliminary evidence to indicate that stem cells reside in the interpalisade (of Vogt) rete ridges. This concept was supported by Goldberg and Bron ${ }^{16}$ and Townsend. ${ }^{17}$ The structure of the palisades and the rete ridges, their vascularity and pigmentation are all analogous to repositories of stem cells in the monkey palm epidermis. ${ }^{14}$

The alternating curvilinear columns of stained and unstained cells that extend form the limbus towards the corneal centre seen in the whorls, would support the view outlined above, that cell division and migration from the periphery to the centre are not uniform along the limbal circumference. When limbal palisades were visible, the cell columns appeared to correspond to interpalisade rete ridges. A similar streaming of cells onto grafted corneas occurring in relation to broken sutures has been reported before ${ }^{18}$ and was also noted in this study. These observations lend support to the belief that stem cell activity does not occur contiguously along the limbus, but rather in an interrupted manner presumably corresponding to repositories of stem cells in the rete ridges. Such radially disposed columns when subjected to a torsional influence-for instance, of ocular magnetic fields, would form a whorled pattern.

The whorl pattern is sustained as long as the stimulus for increased cell turnover is maintained. Once this stimulus is eliminated, the pattern tends to resolve spontaneously. Although no lasting sequelae were noted in the majority of patients, the occurrence of persistent epithelial defects and nebular scarring noted in some patients, is a cause for concern. This perhaps suggests that an attempt to eliminate the cause for hurricane keratopathy should be made where possible.

1 Bron AJ. Vortex patterns of the corneal epithelium. Trans Ophthalmol Soc UK 1973;93:455-72.

2 Lemp MA, Mathers WD. Corneal epithelial cell movement in humans. Eye 1989;3:438-45.

3 Bloch FJ. Vortex-shaped dystrophy of the cornea. Arch Ophthalmol 1940;23:825-8.

4 Mackman GS, Polack FM, Sydrys L. Hurricane keratitis in penetrating keratoplasty. Cornea 1983;2:31-4.

5 Dua HS, Watson NJ, Mathur RM, et al. Corneal epithelial cell migration in humans: hurricane and blizzard keratopathy. Eye 1993;7:53-8.

6 Dua HS, Forrester JV, Cohen EJ, et al. Clinical observations on corneal epithelial cell migration in humans. Invest $O p h$ halmol Vis Sci 1993;S34:1017.

7 Dua HS, Singh A, Gomes JAP, et al. Vortex or whorl formation of cultured human corneal epithelial cells induced by magnetic fields. Eye 1996;10:447-50.

8 Charap AD. Corticosteroids. In: Tasman W, Jaeger EA, eds. Duane's foundations of clinical ophthalmology. Philadelphia: Lippincott, 1992; Vol 3, chapter 31:31-2.

9 Abelson MB, Butrus S. Corticosteroids in ophthalmic practice. In: Albert DM, Jakobiec FA, eds. Principles and practice of ophthalmology. Basic sciences. Philadelphia: Saunders, of ophthalmology. Basic scien
1994; Chapter 82:1018-19.

10 Buxton JN. Contact lenses in keratoconus. Contact Intraocular Lens Med f 1978;4:74-85.

11 Fiol-Silva Z. Management of keratoconus. In: Stein HA, Freeman ML eds. Contact lens challenges, ophthalmology clinics of North America. Philadelphia: Saunders, 1996;9:83-6.

12 Lopatynsky MO, Cohen EJ, Leavitt KG, et al. Corneal topography for rigid gas permeable lens fitting after penetrating keratoplasty. CLAO ₹ 1993;19:41-4.

13 Mathers WD, Lemp MA. Vortex keratopathy of the corneal graft. Cornea 1991;10:93-9.

14 Tseng SCG. Concept and application of limbal stem cells. Eye 1989;3:141-57.

15 Davanger M, Evensen A. Role of the pericorneal papillary structure in renewal of corneal epithelium. Nature 1971; 229:560-1.

16 Goldberg MF, Bron AJ. Limbal palisades of Vogt. Trans Am Ophthalmol Soc 1982;80:155-71.

7 Townsend WM. The limbal palisades of Vogt. Trans Am Ophthalmol Soc 1991;89:721-56.

18 Dua HS, Gomes JAP, Singh A. Corneal epithelial wound healing. Br F Ophthalmol 1994;78:401-8. 